\title{
Network Properties Revealed during Multi-Scale Calcium Imaging of Seizure Activity in Zebrafish
}

\author{
(1)Jing Liu and ${ }^{D}$ Scott C. Baraban
}

https://doi.org/10.1523/ENEURO.0041-19.2019

Department of Neurological Surgery and Weill Institute for Neuroscience, University of California, San Francisco, CA 94143

\begin{abstract}
Seizures are characterized by hypersynchronization of neuronal networks. Understanding these networks could provide a critical window for therapeutic control of recurrent seizure activity, i.e., epilepsy. However, imaging seizure networks has largely been limited to microcircuits in vitro or small "windows" in vivo. Here, we combine fast confocal imaging of genetically encoded calcium indicator (GCaMP)-expressing larval zebrafish with local field potential (LFP) recordings to study epileptiform events at whole-brain and single-neuron levels in vivo. Using an acute seizure model (pentylenetetrazole, PTZ), we reliably observed recurrent electrographic ictal-like events associated with generalized activation of all major brain regions and uncovered a well-preserved anterior-toposterior seizure propagation pattern. We also examined brain-wide network synchronization and spatiotemporal patterns of neuronal activity in the optic tectum microcircuit. Brain-wide and single-neuronal level analysis of PTZ-exposed and 4-aminopyridine (4-AP)-exposed zebrafish revealed distinct network dynamics associated with seizure and non-seizure hyperexcitable states, respectively. Neuronal ensembles, comprised of coactive neurons, were also uncovered during interictal-like periods. Taken together, these results demonstrate that macro- and micro-network calcium motifs in zebrafish may provide a greater understanding of epilepsy.
\end{abstract}

Key words: epilepsy; fast confocal; neuronal networks; synchronization; whole-brain imaging; zebrafish

\section{Significance Statement}

Monitoring the dynamic activities in large-scale neuronal networks is critical to understanding seizure initiation and propagation. Here, we used well-established larval zebrafish seizure protocols and fast confocal imaging of genetically encoded calcium indicator (GCaMP)-expressing fish to investigate the epileptic network properties at brain-wide and single-cell levels. We revealed the rapid propagation of seizure activity from anterior-to-posterior brain regions in zebrafish CNS. We also showed that microensembles of neuronal subpopulations are active during interictal-like periods in a manner similar to that seen in human electrophysiology data sets. Our findings demonstrate that these non-invasive optical imaging approaches will advance our understanding of the network basis underlying seizures and facilitate the development of methods to suppress these events.

\section{Introduction}

Synchronization of neuronal networks is a commonly observed event in the brain and underlies pathologic generation and propagation of epileptic seizures. Although

\footnotetext{
Received February 5, 2019; accepted February 8, 2019; First published February 25, 2019.

S.C.B. is a co-Founder and Scientific Advisor for EpyGenix Therapeutics. J.L. declares no competing financial interests.
}

electrophysiological features of an individual seizure event are well characterized using local field potential (LFP) and/or single-unit electrophysiological recordings (Grasse et al., 2013; Park et al., 2013; Schmidt et al., 2014; Truccolo et al., 2014; Weiss et al., 2016), these

Author contributions: J.L. and S.C.B. designed research; J.L. and S.C.B. performed research; J.L. analyzed data; J.L. and S.C.B. wrote the paper. 
approaches do not capture brain-wide spatiotemporal network dynamics underlying these events. Efforts to image these networks have primarily been limited to small microcircuits contained within brain slice preparations or imaging "windows" in head-restrained mice (Trevelyan et al., 2006; Muldoon et al., 2013, 2015; Grosser et al., 2014; Kuzum et al., 2014; Hongo et al., 2015; Lillis et al., 2015; Rossi et al., 2017; Wenzel et al., 2017; Liou et al., 2018). Recent advances in imaging technology combined with stable expression of genetically encoded calcium indicators (GCaMPs; Tian et al., 2009; Akerboom et al., 2012; Chen et al., 2013) have led to a revolution in brain-wide activity mapping. GCaMPs are employed in a range of model organisms; among these, larval zebrafish (Danio rerio) offer an unparalleled combination of higher vertebrate relevance (including human), optical transparency, and a small brain size (comprising $\sim 100,000$ neurons) allowing spatial coverage of multiple brain regions. Moreover, the availability of transgenic zebrafish, in which GCaMPs are under the control of neuronal elavl3 or NeuroD promoters has greatly facilitated the potential for assessing neural networks. Indeed, brain-wide imaging in GCaMP-expressing zebrafish has already been used to monitor spatiotemporal patterns of neural activity during fictive swimming (Ahrens et al., 2013a; Thiele et al., 2014), motor adaptation (Ahrens et al., 2012), visual processing (Akerboom et al., 2012; Muto et al., 2013), and prey capture (Muto and Kawakami, 2013; Semmelhack et al., 2014). During this time, zebrafish have also emerged as a valuable vertebrate model for neurologic disease, particularly for epilepsy (Hortopan et al., 2010; Ramirez et al., 2012; Stewart et al., 2014; Grone and Baraban, 2015; MartínJiménez et al., 2015; Griffin et al., 2017). Combining these advances, it is now possible to non-invasively monitor activity throughout the zebrafish nervous system during an epileptic seizure event.

Brain-wide imaging during seizures, in contrast to invasive electrophysiological recordings, increases the likelihood that network patterns will be discovered. To this end, we combined well-established acute seizure (pentylenetetrazole; PTZ; Baraban et al., 2005; Baxendale et al., 2012; Afrikanova et al., 2013; Buenafe et al., 2013; Orellana-Paucar et al., 2013; Rahn et al., 2014; Siebel et al., 2015; Barbalho et al., 2016; Copmans et al., 2018) and non-seizure hyperexcitability (4-aminopyridine; 4-AP)

This work was supported by National Institutes of Health/National Institute of Neurological Disorders and Stroke Grants R01-NS096976 and R01-NS103139 and by a University of California San Francisco - University of California Berkeley (UCSF-UCB) Sackler Family Exchange sabbatical fellowship (to S.C.B.).

Acknowledgements: We thank Ehud Isacoff and members of the Isacoff laboratory (Claire Oldfield and Carlos Pantoja) at University of California Berkeley for early training and guidance using $3 i$ imaging calcium imaging strategies in larval zebrafish.

Correspondence should be addressed to Scott C. Baraban at scott.baraban@ucsf.edu.

https://doi.org/10.1523/ENEURO.0041-19.2019

Copyright $\odot 2019$ Liu and Baraban

This is an open-access article distributed under the terms of the Creative Commons Attribution 4.0 International license, which permits unrestricted use, distribution and reproduction in any medium provided that the original work is properly attributed. models (Ellis et al., 2012; Kumar et al., 2016; Cassar et al., 2017; Winter et al., 2017) with spinning disk confocal microscopy, enabling fast (20-30 fps) in vivo imaging of network events. Imaging studies were performed at brainwide and single-cell resolution levels. As anesthetics can modify neuronal activity (Greenberg et al., 2008), experiments were done using "awake" agarose-embedded larval zebrafish paralyzed with pancuronium to reduce movement artifact. Simultaneous measurements of LFPs were used to confirm seizure activity. By analyzing brainwide changes in calcium dynamics in an acute seizure model, we revealed neuronal populations in telencephaIon initiating ictal-like seizure events that rapidly generalized to all CNS regions. The spatiotemporal patterns of calcium signal showed a rapid propagation of seizure activity from anterior-to-posterior brain regions. Subsequent analysis of spontaneous activity patterns established a clear pattern of synchronization during ictal-like seizure events consistent with a long-standing notion that seizures are a manifestation of hypersynchronous neural networks. Automated calcium signal processing and spike detection confirmed this high degree of synchronization at a single-neuron level. Finally, we showed that neuronal ensembles (Tao et al., 2011; Truccolo et al., 2011, 2014; Miller et al., 2014) are active during interictallike periods. We suggest that these non-invasive optical imaging approaches could provide a more comprehensive understanding of complex neuronal networks involved in the generation and propagation of seizures.

\section{Materials and Methods}

\section{Zebrafish lines}

All procedures followed National Institute of Health and the University of California, San Francisco guidelines and were approved by the Institutional Animal Care and Use Committee. Calcium imaging experiments were performed on the Tg(neurod1:GCaMP6f) line (Rupprecht et al., 2016) in the nacre ( $\mathrm{mitfa}^{-/}$) background (kindly provided by Dr. C. Wyart from Institut du Cerveau et de la Moelle Épinière, Paris) on 5-6 d postfertilization (dpf). Adult zebrafish were maintained at $28^{\circ} \mathrm{C}$ on a $14 / 10 \mathrm{~h}$ light/dark cycle following standard methods. Larvae were raised in embryo media consisting of $0.03 \%$ Instant Ocean (Aquarium Systems, Inc.) and $0.0002 \%$ methylene blue in reverse osmosis-distilled water. At 5-6 dpf, zebrafish have not yet experienced sexual differentiation (Liew and Orbán, 2014).

\section{Calcium imaging and electrophysiology}

Zebrafish larvae were paralyzed in $300 \mu \mathrm{M}$ pancuronium (Abcam), and then immobilized in a drop of $2 \%$ low-melting point agarose in a recording chamber (Fig. $1 A$ ). The recording chamber was placed on the stage of a Zeiss Axiocam upright microscope using a $5 \times$ or $20 \times$ objective (for whole-brain and neuron-level imaging, respectively), Yokogawa CSU-X1 Spinning Disk Confocal and a 470-nm laser light source (3i LaserStack). The recording chamber was filled with embryo media containing pancuronium $(300 \mu \mathrm{M})$. Epileptiform activities were induced by bath application of PTZ $(10 \mathrm{mM}$; Sigma- 
A

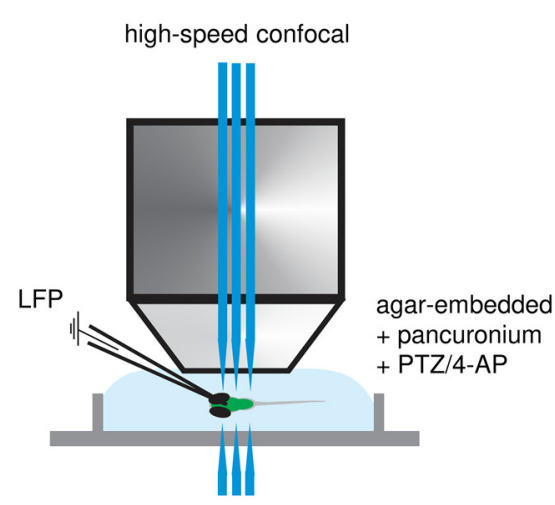

B

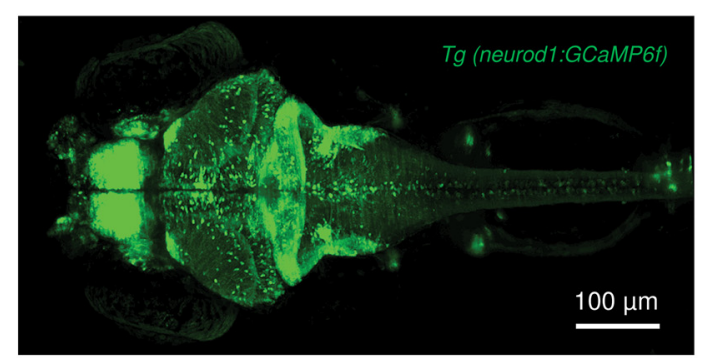

C

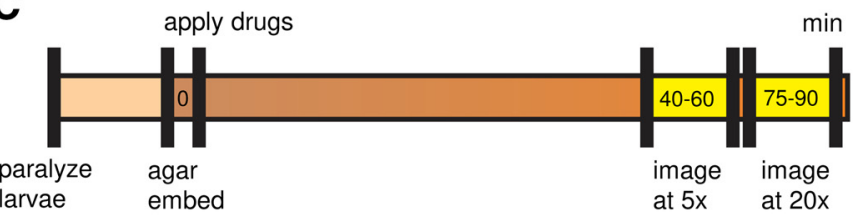

D

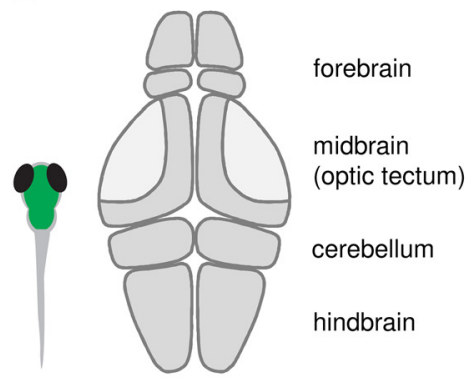

F

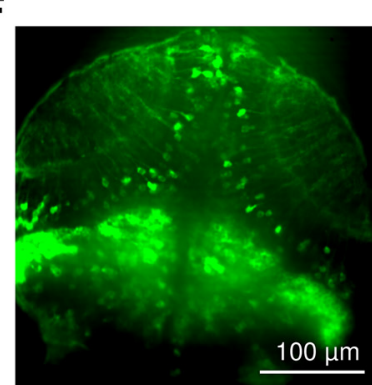

E
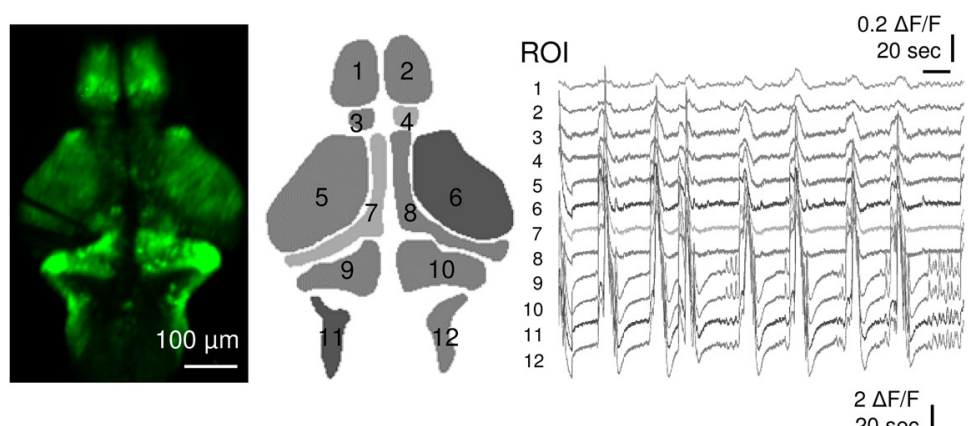
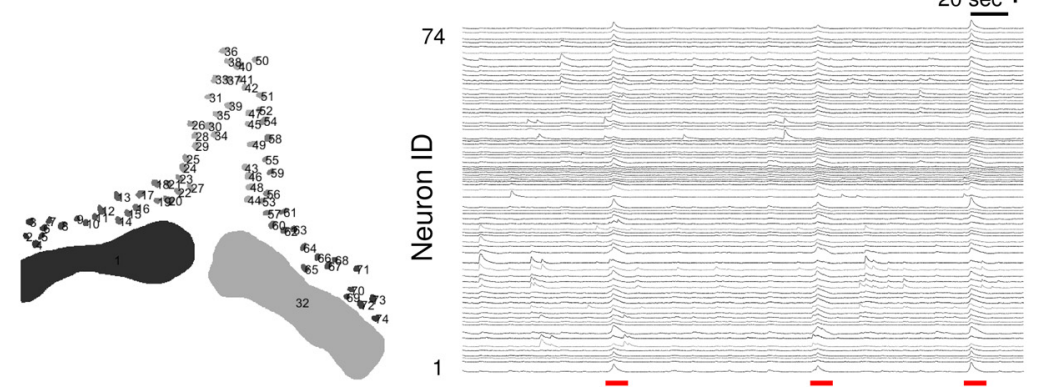

Figure 1. High-speed confocal calcium imaging at different scales. A, Experimental setup. Simultaneous LFP recording and fast confocal imaging (20-30 fps) in agar-embedded larval zebrafish exposed to pancuronium (300 $\mu \mathrm{M})$ with PTZ (10 mM) or 4-AP (4 mM). $\boldsymbol{B}$, Representative high-resolution imaging of neurod1:GCaMP6f expressed larval zebrafish on 5-6 dpf. C, Experimental workflow. Recordings were obtained $\sim 40$ min after drug application, and $5 \times$ and $20 \times$ objectives were used for whole-brain and neuron-level imaging, respectively. $\boldsymbol{D}$, Schematic illustration depicting sub-regions of the larval zebrafish brain. E, ROls and representative calcium traces $(\Delta F / F)$ of PTZ-induced ictal-like events; 1, 2: pallium; 3, 4: habenula; 5, 6: neuropil; 7, 8: SPV; 9, 10: cerebellum; 11, 12: hindbrain. $\boldsymbol{F}$, Neuronal microcircuits within optic tectum and representative calcium traces of individual SPV neurons with PTZinduced ictal-like event break-ins (underlined in red). Cerebellum was included as an indicator of ictal-like events that involve all brain regions. Scale bars as indicated in figure.

Aldrich) or 4-AP (4 mM; Sigma-Aldrich), and the fish were allowed to establish consistent epileptiform activities for at least 40 min before imaging studies were initiated (Fig. 1C). Images of $512 \times 512$ pixels were acquired at 20-30 $\mathrm{Hz}$ with an EMCCD camera (Photometrics Evolve). Multiple 5-min recordings (6000-9000 frames) were acquired for each experiment using SlideBook software (3i Intelligent Imaging Innovations). To record LFPs, a glass microelectrode was placed under visual guidance in the optic tectum or cerebellum. Electrodes were filled with $2 \mathrm{M}$ $\mathrm{NaCl}$, and electrical activity was recorded using an Axopatch 1D amplifier (Molecular Devices). Voltage records were lowpass filtered at $1 \mathrm{kHz}$ (-3 dB, 8-pole Bessel), high-pass filtered at $0.1 \mathrm{~Hz}$, digitized at $10 \mathrm{kHz}$ using a Digidata $1520 \mathrm{~A} / \mathrm{D}$ interface, and stored on a PC computer running Axoclamp software (Molecular Devices).

\section{Image analysis}

The raw images were first processed to correct motion drift using the Template Matching image registration plugin for ImageJ. Regions of interest (ROIs) for brain regions and single neurons were manually segmented with the ROI manager of ImageJ (Fig. 1E,F). Corrected image stacks and ROI segmentation file were then imported to MATLAB (MathWorks) for calcium fluorescence signal extraction and analysis using the FluroroSNNAP software 
(Patel et al., 2015). The calcium fluorescence signal for each brain region/neuron was obtained by averaging all pixels within the ROI. The fluorescence changes $(\Delta F / F)$ were calculated by subtracting each data point with the mean of the lower $50 \%$ of values within previous 10 -s sliding window and normalized to the mean of the lower $50 \%$ of values within previous 10 -s sliding window. Automated event detection was performed with the template-matching algorithm (Schultz et al., 2009) included in the FluroroSNNAP. A time-varying correlation coefficient between fluorescence trace and calcium transient templates (from the event wave form library) was calculated. Fluorescence transients with amplitude $\Delta \mathrm{F} / \mathrm{F}>0.1$ and correlation coefficient $>0.85$ were identified as events. Local maxima of the correlation coefficient trace identify the timestamps of calcium events. Since the algorithm may sometimes give errors, the event train was then manually corrected by deleting falsely detected events and adding events missed by the algorithm.

To determine the correlation between simultaneous calcium activity and LFP, the amplitude and duration of ictal-like seizure events in PTZ-treated zebrafish were evaluated. The amplitude is the absolute value of the maximum event peak, and the duration is the interval between the first and last points of the trace leaving and returning the baseline.

\section{Network synchronization}

Whole-brain network synchronization was evaluated with the network analysis module of FluroroSNNAP.

Based on the instantaneous phase of the fluorescence trace of each brain region, a pair-wise phase synchronization matrix was generated to identify patterns of network activity (Patel et al., 2015). According to the matrix, an eigenvalue-based algorithm was applied to calculate the global synchronization index which range from 0 (noncoordinated activity) to 1 (completely synchronized activity). For mathematical details see (Li et al., 2007). Briefly, the eigenvalues of the synchronization matrix were calculated and then normalized to generate an array of synchronization indices. The largest entry in this array is the global synchronization index. If the time series are fully uncorrelated, all elements in the synchronization matrix would be 0 , and the eigenvalue would be 0 , resulting a global synchronization index equal to 0 . Alternatively, if the network was completely synchronized, all elements in the synchronization matrix would be 1 , and the maximal eigenvalue would be equal to the number of time series with other eigenvalues falling to zero, resulting a global synchronization index equal to 1 .

\section{Seizure propagation}

To determine the recruitment timing of each brain region to an ictal-like event, we took the time derivative (slope) of the fluorescence trace (smoothed by taking moving average of 50 data points), and used the local maxima (the fastest change in fluorescence) to identify the onset time point (Wenzel et al., 2017). Each brain region has two data points corresponding to the left and right counterparts. We then calculated the relative lag of each brain region with respect to the earliest onset within an ictal-like event and normalized it to the interval between the earliest onset and the latest onset. Normalized relative lags within an ictal-like event were divided into three quantile groups (first third, early; second third, middle; third third, late), and the probability of each brain region falling into each quantile group was calculated.

\section{Detection of ensemble events}

Ensemble events were defined as coactivation of a group of neurons in which a statistically significant number of neurons are active compared with surrogate datasets. We used a sliding window to generate a time series of coactivation of neurons by counting the number of events within a 0.5-s (10 frames) window. The binary event data were shuffled 2000 times within neurons, and the sliding window counting was performed. Frames with an observed number of coactive neurons $>99.9 \%$ of all surrogate values $(p<0.001)$ were identified as highly active frames with ensemble event. To analyze the spatial extent of neuronal ensembles, the distances between the ensemble centroid and individual neurons within the ensemble were calculated using standard Euclidian distances.

\section{Experimental design and statistical analysis}

We used one-way ANOVA with Holm-Sidak post hoc analysis for multiple variable comparison, and $\chi^{2}$ test for onset timing distribution analysis, which were performed in Prism (GraphPad Software). Correlation coefficients $\left(R^{2}\right)$ between calcium and electrical signals were calculated in MATLAB (MathWorks). Detection of neuronal ensembles was performed in MATLAB by comparing with surrogate datasets (see Materials and Methods). Individual analyses are described in Results.

\section{Results}

To study synchronized neural networks, we used two well-characterized pharmacological models employing bath application of PTZ $(10 \mathrm{mM})$ or $4-\mathrm{AP}(4 \mathrm{mM})$. These acute chemoconvulsant models work through different mechanisms: (1) PTZ acts as a $\mathrm{GABA}_{\mathrm{A}}$ receptor antagonist to disinhibit network activity (Baraban et al., 2005; Baxendale et al., 2012; Afrikanova et al., 2013; Buenafe et al., 2013; Orellana-Paucar et al., 2013; Rahn et al., 2014; Siebel et al., 2015; Barbalho et al., 2016; Copmans et al., 2018) and (2) 4-AP is a potassium channel blocker that enhances neuronal firing activity (Ellis et al., 2012; Kumar et al., 2016; Cassar et al., 2017; Winter et al., 2017). Together, these acute models provide a strategy to study recurrent spontaneous seizure events (PTZ) and non-seizure hyperexcitability (4-AP), respectively.

\section{Multi-scale imaging of epileptiform activity}

High-speed confocal microscopy was used to monitor ictal-like activity in agar-embedded larval zebrafish (Fig. $1 A$ ) with neuronal expression of GCaMP (neurod1: GCaMP6f; Fig. 1B). Larvae were immobilized in agar and imaged using a $5 \times$ (brain-wide) or $20 \times$ (single-cell) objective. For brain-wide studies, the confocal plane of view was adjusted to include forebrain (contains pallium and habenula), optic tectum (contains neuropil and stratum periventriculare; SPV), cerebellum and hindbrain (Fig. 
A

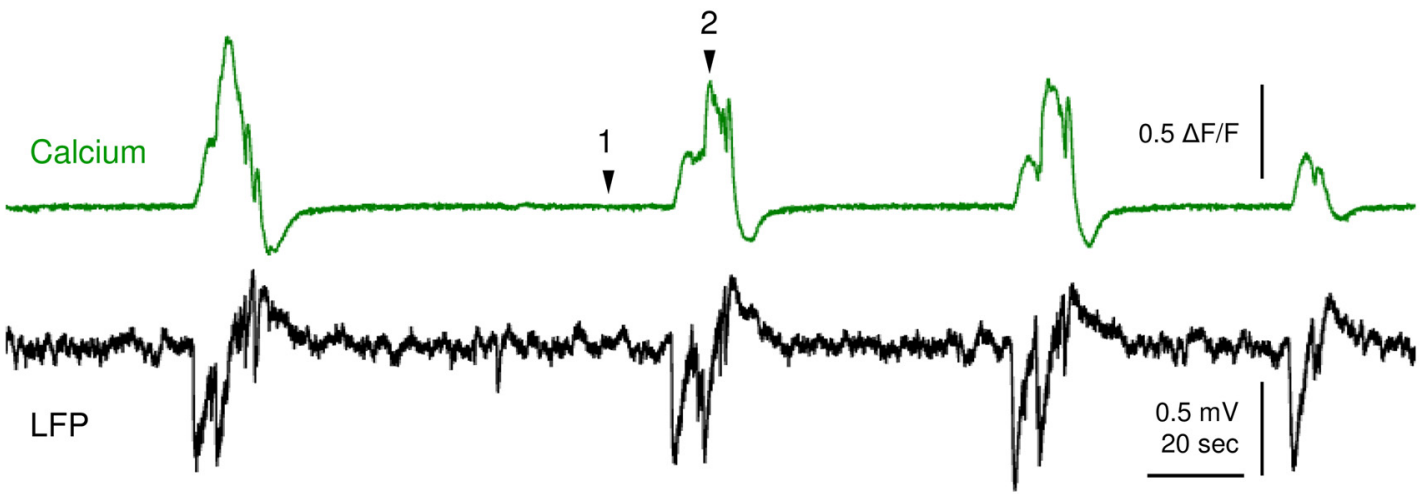

B
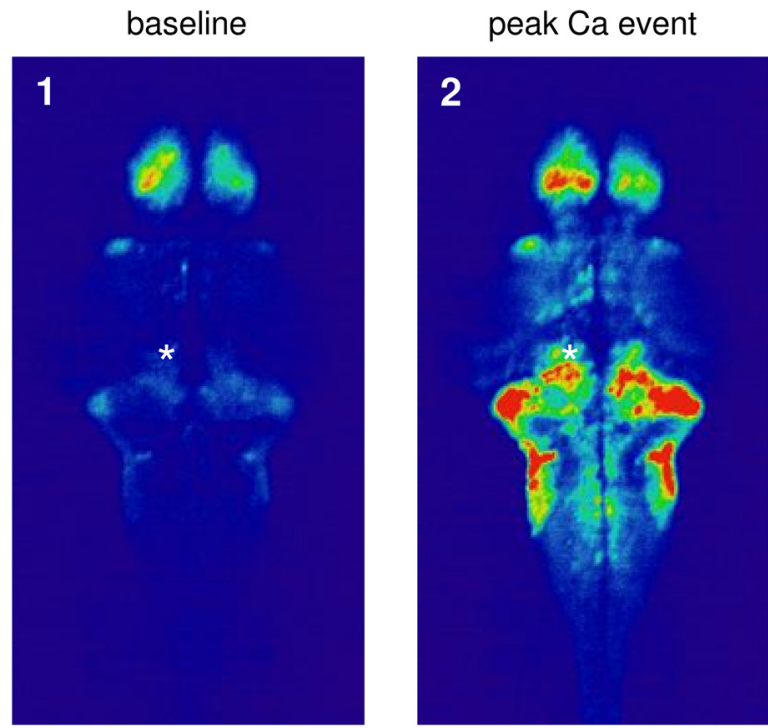

0

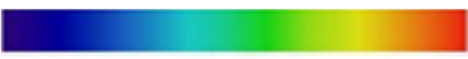

255

Fluorescence intensity
C

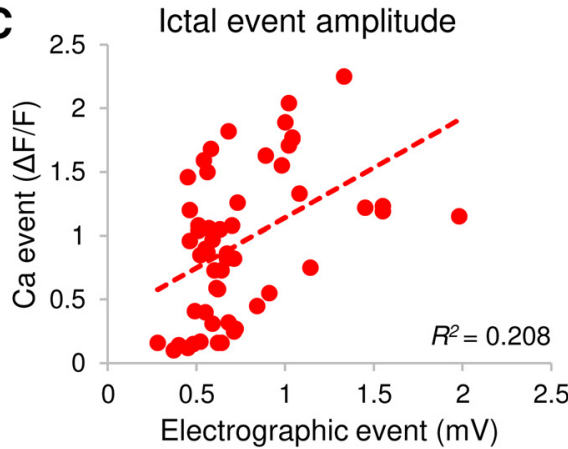

D

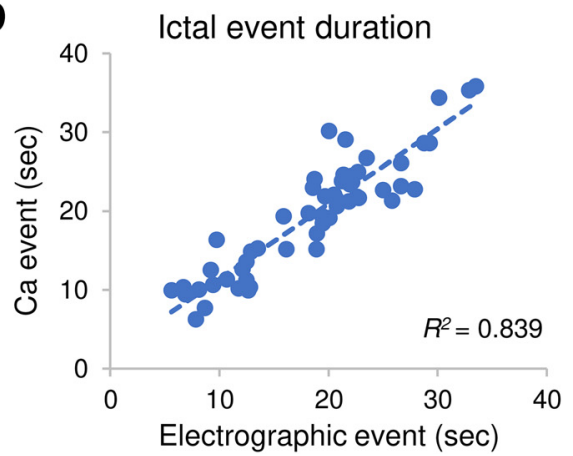

Figure 2. Correlation between LFP and calcium transients. $\boldsymbol{A}$, Representative simultaneous calcium traces (green) from the cerebellum and LFP (black) recorded from optic tectum/cerebellum with recurrent PTZ-induced ictal-like seizures. Scale bars as indicated in figure. $\boldsymbol{B}$, Fluorescence images of calcium activity during baseline and peak ictal-like event. The intensity of fluorescence is color coded as shown in the color bar. Events 1 and 2 as noted in $\boldsymbol{A}$. Asterisk indicates the LFP recording site. $\boldsymbol{C}, \boldsymbol{D}$, Correlation between LFP and calcium transients in ictal-like event amplitude $(\boldsymbol{C})$ and duration $(\boldsymbol{D})$. Corresponding correlation coefficient $R^{2}$ is indicated in figure; $n=54$ events from 10 PTZ-treated larvae.

$1 D, E)$. ROls were drawn manually over anatomic areas corresponding to major brain regions, and fluorescence changes over time $(\Delta \mathrm{F} / \mathrm{F})$ were extracted from time-lapse movies acquired at 20-30 $\mathrm{Hz}$ (Fig. 1E,F). In all PTZexposed larvae $(n=43)$, we observed large calcium transients at a frequency of one to two events per min, which occurred synchronously across all brain ROls consistent with a generalized seizure classification (Fig. 1E; Movie 3). Large calcium transients were not seen in Control larvae bathed in embryo media ( $n=9$; Movie 1). As seizures are commonly associated with increased synchrony in neuronal populations (Penfield and Jasper, 1954; Jiruska et al., 2013), we also monitored calcium activity in SPV neurons within optic tectum microcircuits at single-cell resolution, which is facilitated by the mosaic neurod1-driven expression of GCaMP6f in this brain region (Fig. 1F). Exposure to PTZ elicited waves of calcium activity that showed a high degree of synchrony across all neurons (Movie 6).

To determine whether synchronous calcium events correspond to electrographic discharges, we simultaneously monitored LFPs with an electrode placed in optic tectum SPV or cerebellum (as noted in Fig. 2B) in PTZ-treated larvae. Long-duration multi-spike ictal-like discharges coincided with large-amplitude calcium transients in every recording (Fig. 2A). The correlation between whole-brain calcium transient amplitude and LFP amplitude was low $\left(R^{2}=0.208, n=54\right.$ events from 10 PTZ-treated larvae; Fig. 2C). The relationship between whole-brain calcium transient duration and electrographic event duration was 
A

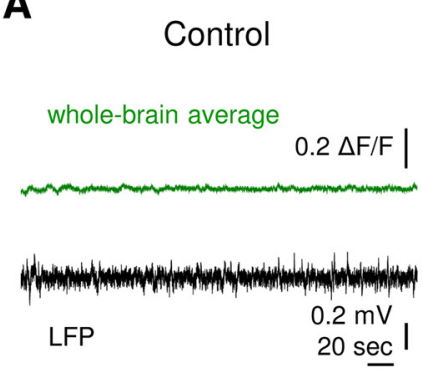

4-AP

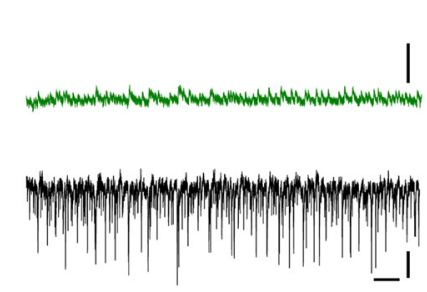

PTZ

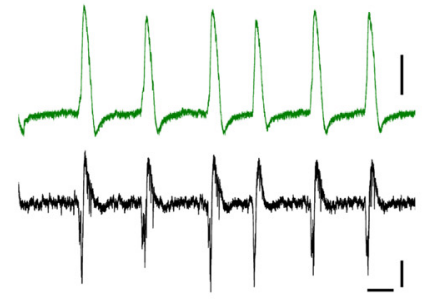

B

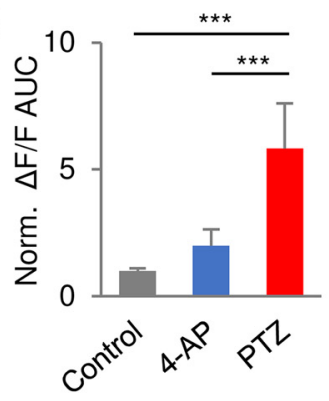

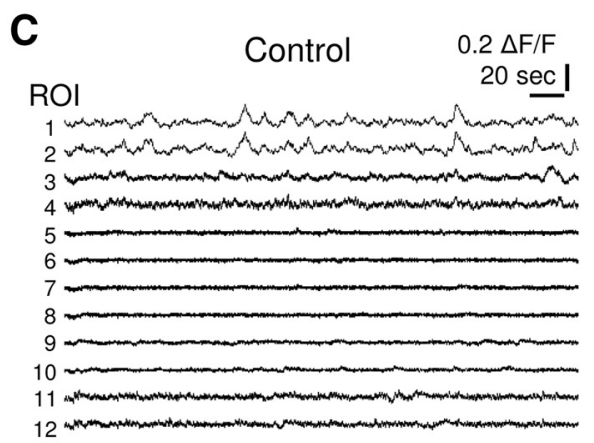

C
D

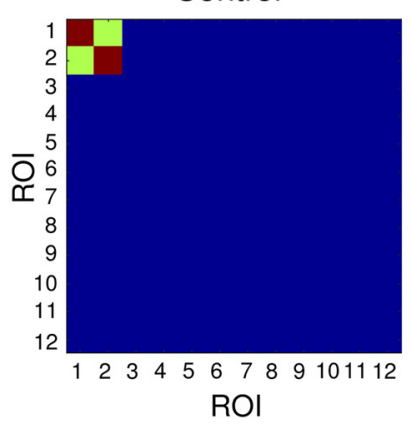

Control

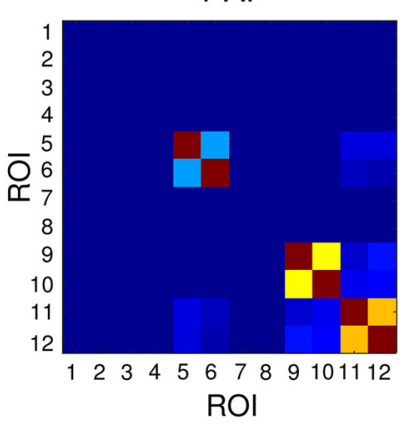

4-AP

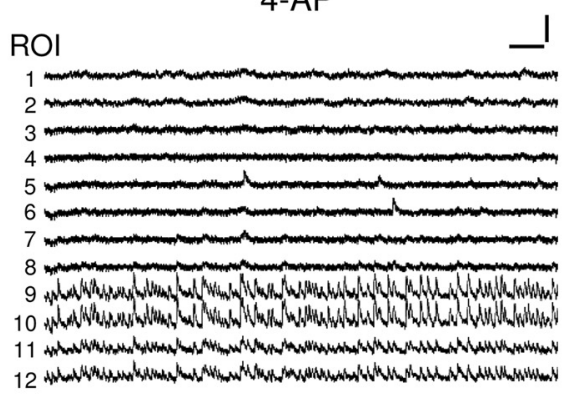

PTZ

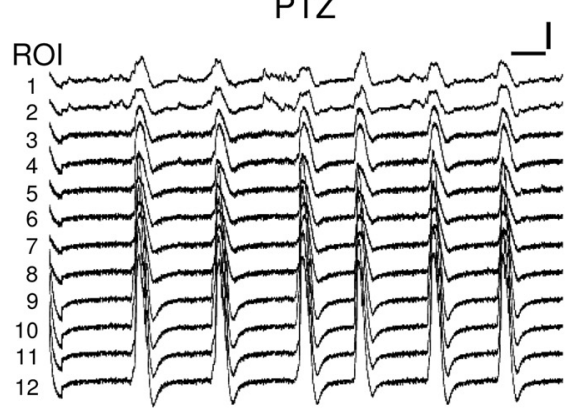

Figure 3. Brain-wide network synchronization. $\boldsymbol{A}$, Representative whole-brain average fluorescence changes ( $\Delta F / F ;$ green) and LFP (black) recorded from control, 4-AP, and PTZ-treated larvae. $\boldsymbol{B}$, Comparison of normalized AUC of fluorescence changes (norm. $\Delta \mathrm{F} / \mathrm{F}$ $A \cup C)$. $\boldsymbol{C}$, Representative fluorescence changes of each brain region under different conditions. ROls refer to Figure $1 E$. $\boldsymbol{D}$, Correlation matrices of whole-brain network activity for representative fish. $\boldsymbol{E}$, Comparison of global synchronization (sync.) index. Scale bars as indicated in figure; $n=4,7$, and 7 fish for control, 4-AP, and PTZ condition, respectively. Error bars indicate SD. Statistical significance is indicated as $* * * p<0.001$.

approximately linear $\left(R^{2}=0.839, n=54\right.$ events from 10 PTZ-treated larvae; Fig. 2D).

\section{Brain-wide network synchronization}

To investigate characteristics of synchronization, we analyzed brain-wide network dynamics in hyperexcitable 4-AP-treated and epileptic PTZ-treated zebrafish. Age-matched untreated larvae were studied as Controls. 4-AP and PTZ-treated larvae showed distinct activity patterns in both whole-brain average fluorescence changes and LFP (Fig. 3A). 4-AP-treated larvae were characterized by high-frequency short-duration spikes in LFP and frequent low-amplitude calcium transients. In contrast, PTZ-treated larvae consistently exhibited recurrent high-amplitude long-duration ictal-like events in both LFP and calcium traces, and significantly increased area under curve (AUC) in fluorescence changes compared with control and 4-AP-treated lar- vae $(p<0.001$, one-way ANOVA; $n=4,7$, and 7 fish for control, 4-AP, and PTZ condition, respectively; Fig. 3B).

Next, we analyzed the activity of subregions within the larval whole-brain network. Representative fluorescence traces of each brain region (ROI numbering refers to Fig. $1 E)$ and corresponding correlation matrices are shown in Figure $3 C, D$. Larvae exposed to 4-AP showed frequent short-duration and low-amplitude calcium transients in cerebellum and hindbrain regions only. In contrast, PTZtreated larvae showed widespread high-amplitude and long-duration calcium transients across the entire nervous system, and significantly increased brain-wide synchronization compared with Control and 4-AP-treated larvae $(p<0.001$, one-way ANOVA; $n=4,7$, and 7 fish for control, 4-AP, and PTZ condition, respectively; Fig. 3E). Whole-brain activity of control, 4-AP, and PTZ-treated fish are exemplified in Movies 1, 2, 3, respectively. 


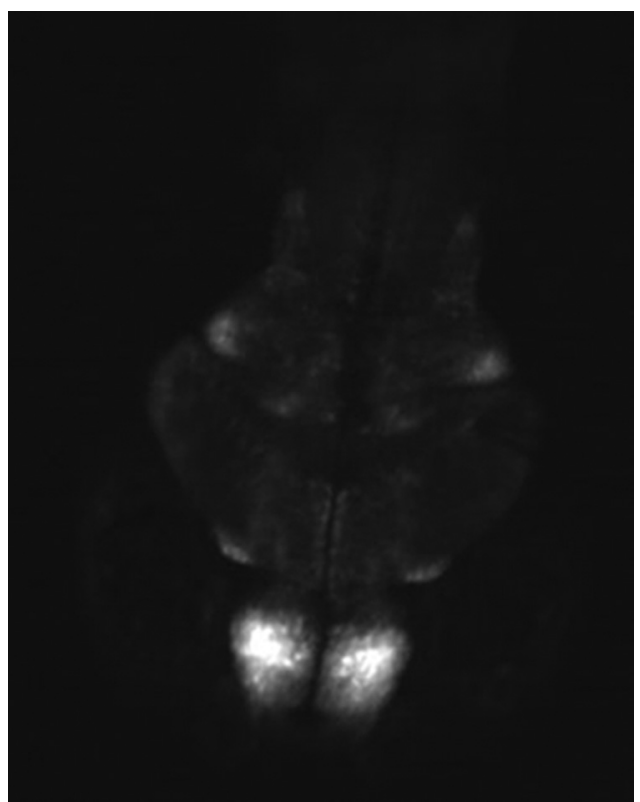

Movie 1. Representative whole-brain imaging with $5 \times$ objective from control fish. Movie played at $5 \times$ speed. [View online]

\section{Seizure propagation}

To determine brain regions recruited during seizure initiation and propagation, we analyzed calcium changes in multiple brain regions (Fig. $1 E$ ) during PTZ exposure $(n=30$ events from 7 PTZ-treated larvae). Figure $4 \mathrm{~A}$ shows representative fluorescence traces of each brain region during an ictal-like event break-in. The red trace is the time derivative of $\Delta \mathrm{F} / \mathrm{F}$ moving average of 50 nearby data points, and the local maxima position corresponds to the onset time point of the brain region. We calculated the

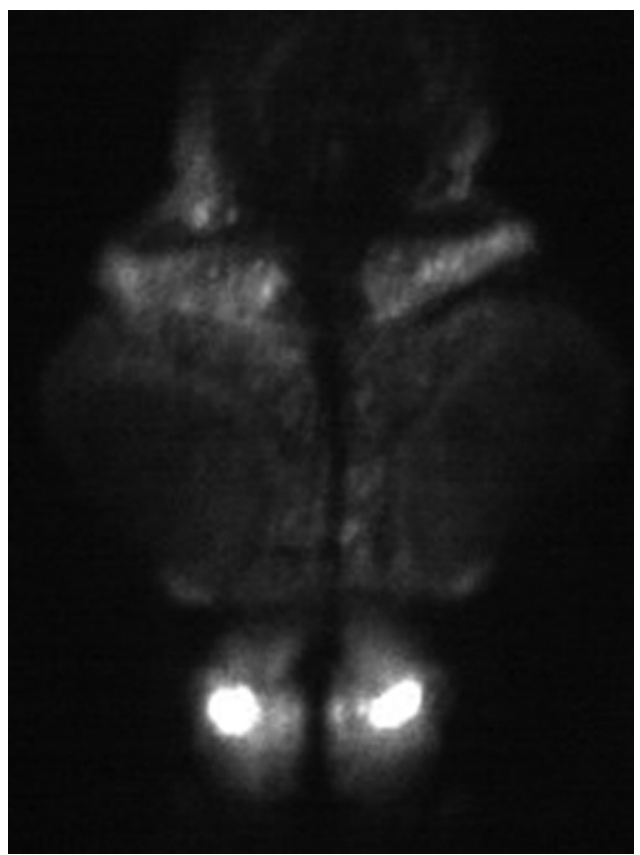

Movie 2. Representative whole-brain imaging with $5 \times$ objective from 4-AP fish. Movie played at $5 \times$ speed. [View online]

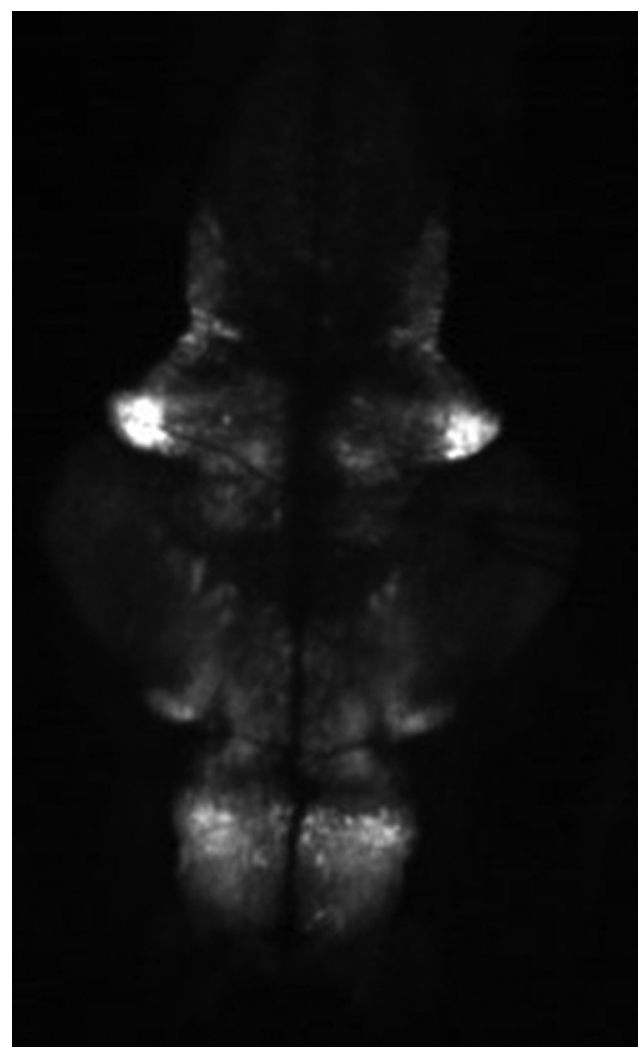

Movie 3. Representative whole-brain imaging with $5 \times$ objective from PTZ fish. Movie played at $5 \times$ speed. [View online]

relative lag of each brain region and normalized it to the earliest-to-latest onsets interval. Arranging the normalized relative lag of brain regions revealed a coarsely preserved temporal ordering across ictal-like seizure events (Fig. $4 B$ ). Figure $4 C$ shows a color-coded onset time mapping from a representative PTZ-induced ictal-like seizure events in one zebrafish (average of four ictal-like events). We then divided the normalized relative lags within one ictal-like event into three quantile groups: early, middle and late (Fig. 4D), and calculated the probability of each brain region falling into each temporal group. This analysis revealed a conserved propagation pattern from the anterior-to-posterior brain $\left(\chi^{2}\right.$ test $\mathrm{X} 2(10)=375.1, p<$ $0.001 ; n=30$ events from seven PTZ-treated larvae; Fig. $4 E)$.

\section{Neuronal ensembles in optic tectum microcircuits}

Next, we investigated network dynamics of the optic tectum microcircuit at single-neuron resolution. We analyzed individual SPV neuronal activity during interictal periods in representative control, 4-AP, and PTZ-treated fish, since ictal-like seizure events involve over $90 \%$ of the neuronal population in the field of view. Cerebellum activity, where baseline neurod1:GCaMP6f expression is prominent (Fig. 1B), was also extracted as a reference of ictal-like events that generalize to the entire nervous system. Based on binary event data generated from fluorescence changes with an automatic event detection algorithm (Patel et al., 2015), we constructed raster plots of neuronal activity, and then used a sliding window tech- 
A

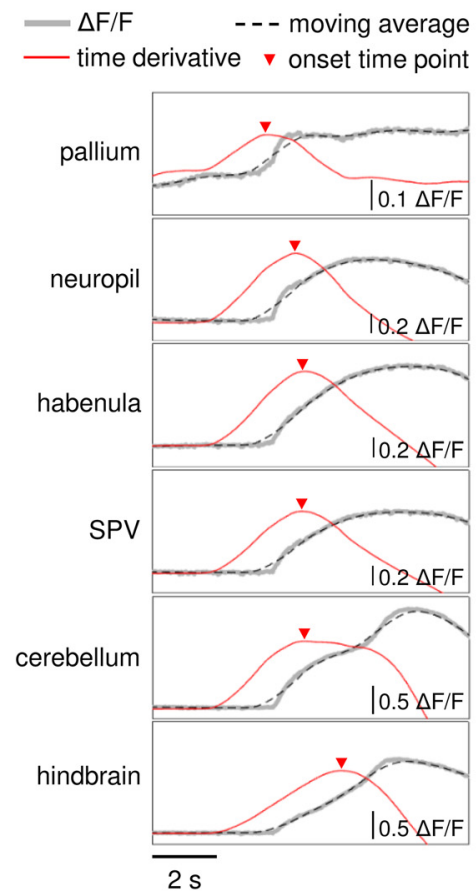

B

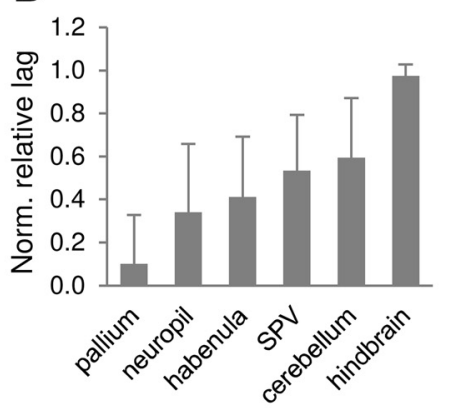

D

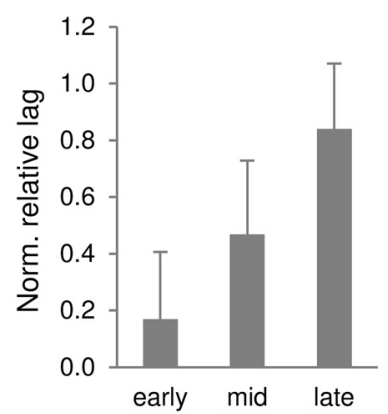

C

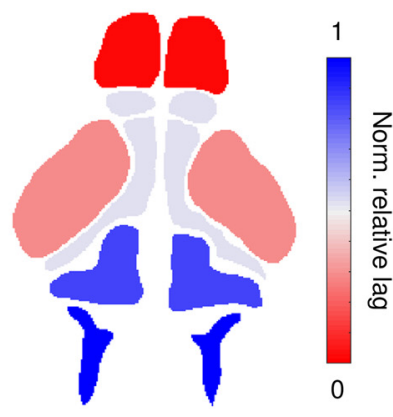

E

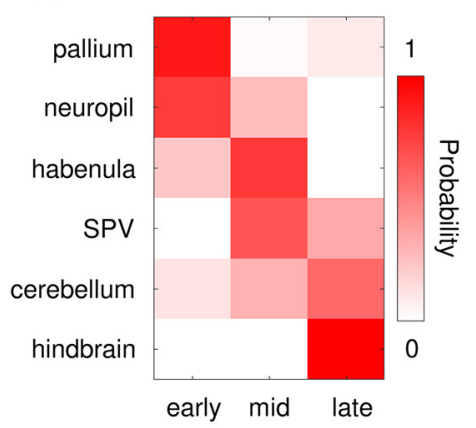

Figure 4. Seizure propagation across the whole-brain. $\boldsymbol{A}$, Representative calcium trace for each brain region within an PTZ-induced ictal-like event. Event onset time points were determined by the local maxima of the time derivative of moving average (of 50 data points) of $\Delta F / F$. Scale bars as indicated in figure. $\boldsymbol{B}$, Plot of normalized (norm.) relative lag from the earliest onset. $\boldsymbol{C}$, Color-coded onset time mapping in a representative fish brain (average of four ictal events). $\boldsymbol{D}$, Normalized relative lag for three quantile groups (first third early onset, second third middle onset, and third third late onset). $\boldsymbol{E}$, Probability of brain regions falling into each quantile group. $\chi^{2}$ test $\mathrm{X} 2(10)=375.1, p<0.001$. Error bars indicate SD; $n=30$ events from 7 PTZ-treated larvae.

nique to generate a coactive neuron number time series (Fig. 5A). Ensemble events, namely a statistically significant number of coactive neurons compared with surrogate datasets, are marked by red arrows (Fig. $5 \mathrm{~A}$, bottom panel), and corresponding coactive neurons are colored red in the raster plot (Fig. 5A, middle panel). Chemoconvulsant (4-AP or PTZ) exposed larvae showed more frequent ensemble event occurrence compared with Controls. The neural firing rate (i.e., number of events in a 5-min recording epoch) distribution shows that both drug exposures increase excitability within the optic tectum network (Fig. 5B). For control fish, most neurons were inactive and firing at a low rate during the recording epoch. For 4-AP-treated fish, about half of the neurons exhibit firing rates between 1 and 10 events per $5 \mathrm{~min}$, with $\sim 20 \%$ of neurons firing $\geq 10$ events per 5 min. For PTZ-treated fish, no neurons were silent and firing rates were between 1 and 8 events per $5 \mathrm{~min}$. Neurons in PTZ-treated fish showed significantly higher average firing rates than control fish, and neurons in 4-AP-treated fish had significantly higher average firing rate than both control and PTZ-treated fish $(p<0.001$, one-way ANOVA; $n=75,76$, and 68 neurons for control, 4-AP, and PTZtreated fish, respectively; Fig. 5 C).

We then analyzed the spatial properties of neuronal ensembles. Representative spatial distribution plots of these ensembles (as noted in Fig. 5A) onto the optic tectum are shown in Figure 5D. Ensembles were detected in all control, 4-AP, and PTZ groups. Figure $5 E$ shows the number of coactive neuron distributions within these ensembles. Control fish data showed few frames with coactive neurons (6000 frames for each recording). While 4-AP-treated fish showed more frames with small coactive neuron groups (number of coactive neurons $<5$ ), consistent with overall network hyperexcitability. PTZ-treated fish had more frames with larger coactive neuron groups (number of coactive neurons $\geq 5$ ) than either Control or 4-AP-treated fish. In an epileptic network that is able to generate ictal-like events (i.e., PTZ-treated fish), spatially distributed ensembles are composed of larger groups of neurons.

The distance between ensemble centroid and each neuron within an ensemble also showed differences between groups (Fig. 5F,G). Ensembles observed in hyperexcitable 4-AP-treated fish network showed significantly larger spatial extent than in control or PTZ-treated fish $(p<0.001$, one-way ANOVA; $n=17,36$, and 42 ensemble neurons for control, 4-AP, and PTZ-treated fish, respectively). Network dynamics of optic microcircuits are exemplified in Movie 4, 5, 6 for control, 4-AP, and PTZtreated fish, respectively.

\section{Discussion}

Here, we combined sensitive GCaMPs and high-speed multi-scale monitoring of brain activity to characterize network dynamics in the CNS of larval zebrafish, following chemoconvulsant treatment. Our experiments revealed that ictal-like seizures are characterized by synchronous activation of the 
A

Control

4-AP

PTZ
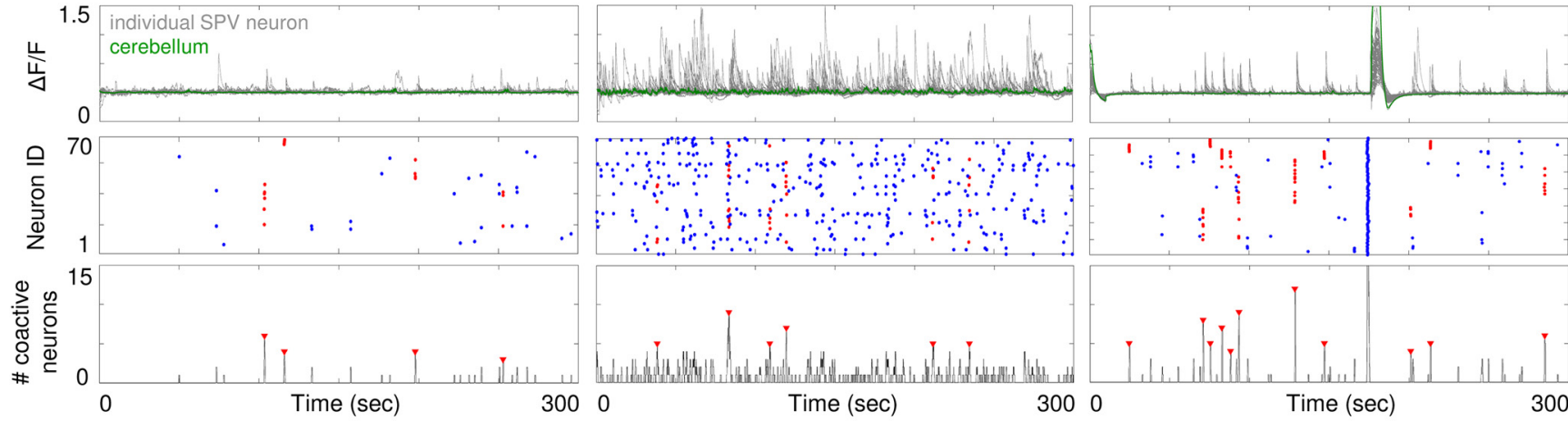

Time (sec)

3000

B

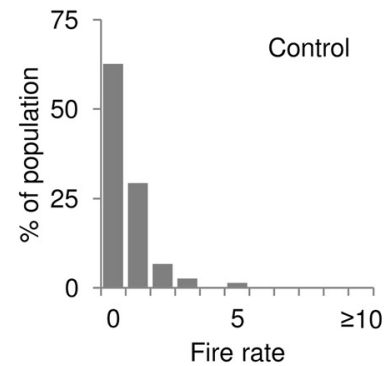

D

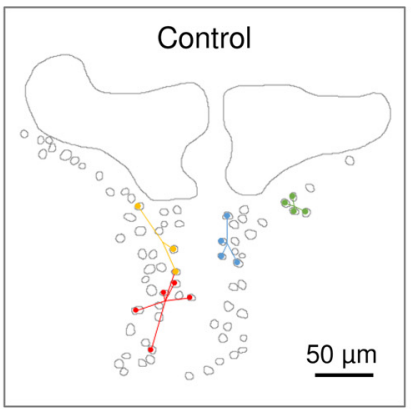

F

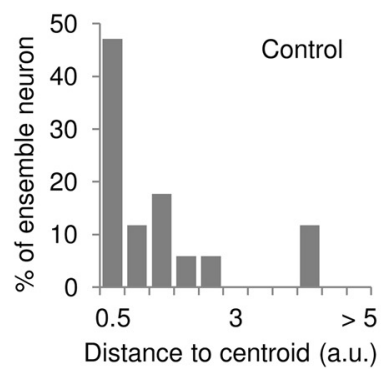

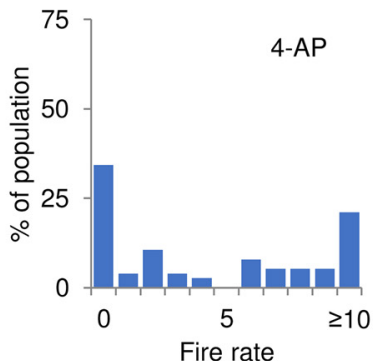

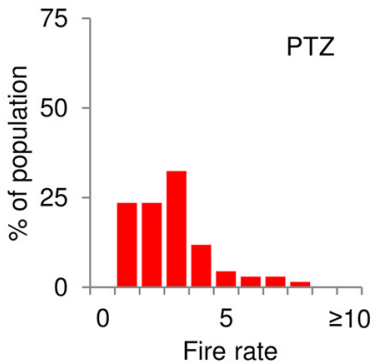

C

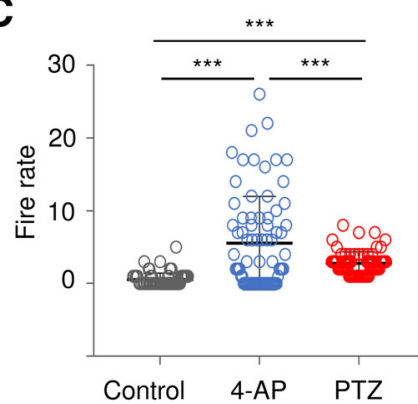

E

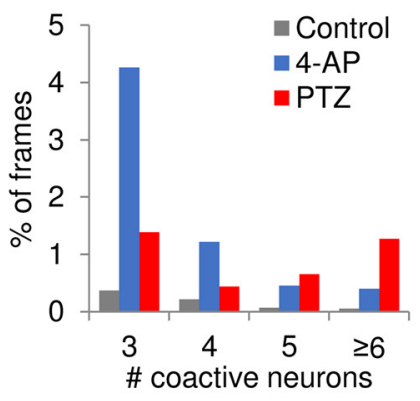

G
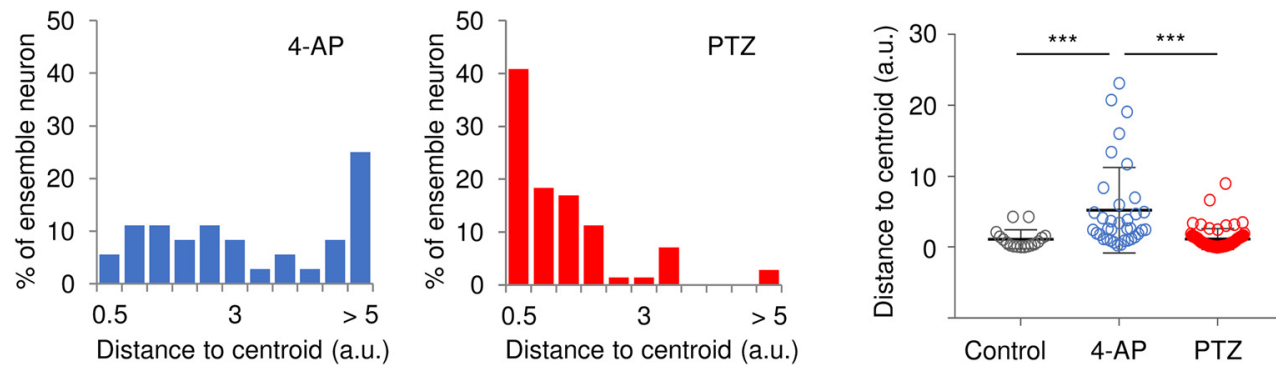

Figure 5. Neuronal ensembles in optic tectum microcircuits. A, Representative calcium traces (gray, individual SPV neuron; green, cerebellum), neuron activation raster plot (red, ensemble neurons) and number of coactive neurons (ensembles were indicated by red arrow) of control, 4-AP, and PTZ-treated fish. Cerebellum activity was shown as an indicator of ictal-like events that involve all brain regions. $\boldsymbol{B}, \boldsymbol{C}$, Histogram $(\boldsymbol{B})$ and distributions $(\boldsymbol{C})$ of the neural firing rate (event count per $5 \mathrm{~min}$ ); $n=75,76$, and 68 neurons for control, 4-AP, and PTZ-treated fish, respectively. $\boldsymbol{D}$, Spatial mapping of ensembles depicted in $\boldsymbol{A}$. Dots in the same color represent coactive neurons, and lines are distances from ensemble neurons to the corresponding ensemble centroid. Each ensemble is indicated by a color. Scale bars as indicated in figure. $\boldsymbol{E}$, Distribution of coactive neuron numbers as percentage of frames $(6000$ frames for each recording). $\boldsymbol{F}, \boldsymbol{G}$, Histogram $(\boldsymbol{F})$ and distributions $(\boldsymbol{G})$ of distances from ensemble neurons to the corresponding ensemble centroid; $n=17,36$, and 42 ensemble neurons for control, 4-AP, and PTZ-treated fish, respectively. Error bars indicate SD. Statistical significance is indicated as $* * * p<0.001$. 


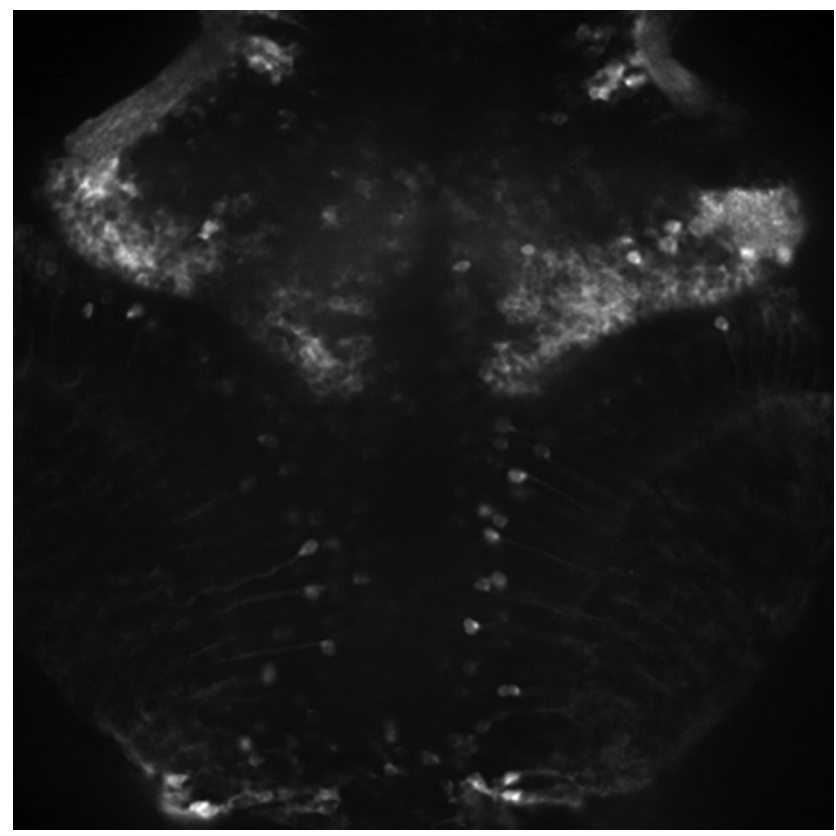

Movie 4. Representative imaging in optic tectum microcircuits with $20 \times$ objective from control fish. Movie played at $5 \times$ speed. [View online]

whole-brain network involving all major brain regions and propagate rapidly in a preserved temporal ordering: from anteriorto-posterior brain. PTZ-induced seizure and 4-AP-induced non-seizure hyperexcitability models showed distinct network dynamics in both whole-brain network and optic tectum microcircuits. Analysis of individual neuronal activities during interictal periods revealed neuronal ensembles in optic tectum, which demonstrated distinct properties in epileptic versus normal brain.

Optical monitoring in larval zebrafish provides a unique opportunity to map neuronal activity in a brain-wide manner. These measurements are not possible with electrophysiological approaches and led to spatiotemporal

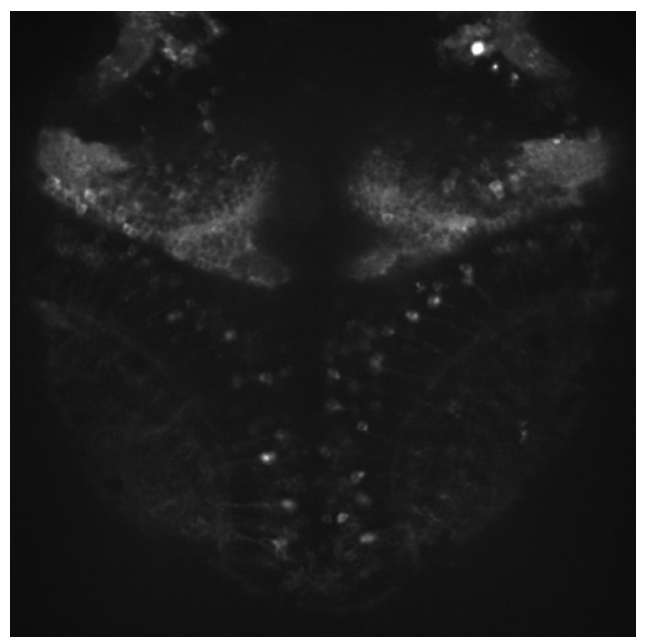

Movie 5. Representative imaging in optic tectum microcircuits with $20 \times$ objective from $4-A P$ fish. Movie played at $5 \times$ speed. [View online]

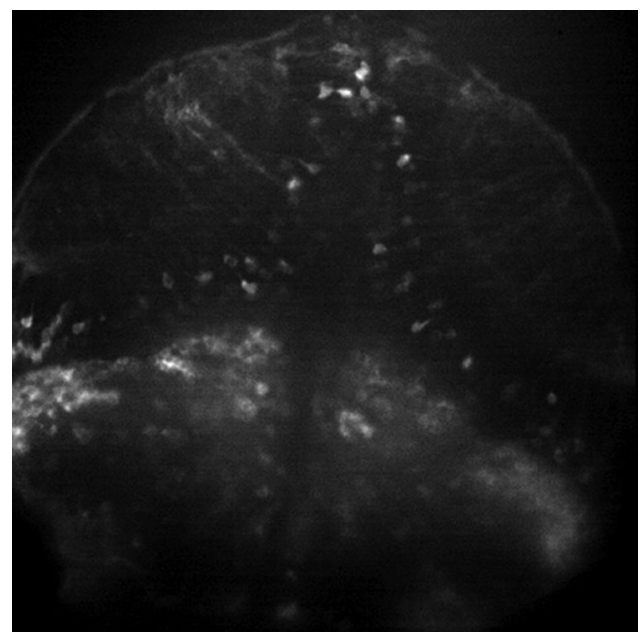

Movie 6. Representative imaging in optic tectum microcircuits with $20 \times$ objective from PTZ fish. Movie played at $5 \times$ speed. [View online]

analysis of seizure initiation and propagation across the zebrafish CNS. Previous imaging studies using an acute PTZ seizure model in zebrafish focused on optical mapping of seizure propagation (Tao et al., 2011) or brain activities coincident with tail movements (Turrini et al., 2017), using mathematical modeling to reveal network connectivity changes during seizures (Rosch et al., 2018), and functional profiling of drug action in multiple brain regions (Winter et al., 2017). Generalized brain-wide activation during ictal-like seizure events was reported in these studies using acquisition speed ranges from 1 to 20 $\mathrm{Hz}$. Here, using a fast spinning-disk confocal we observed similar patterns of brain activity with acquisition speeds up to $30 \mathrm{~Hz}$ and discovered a reproducible anterior-toposterior propagation pattern of rapidly generalized optical seizures (Fig. 4).

To confirm the correlation between electrographic and optical activity, we acquired LFP and calcium imaging data simultaneously (Fig. 2). A high degree of correlation was observed in event duration but not in event amplitude (Fig. 2C,D). This is not surprising, as LFP event amplitude is dependent on electrode tip position in the brain relative to sources and sinks of current (Buzsáki et al., 2012), and calcium signal amplitude is linked to focal plane and GCaMP expression intensity variabilities between fish. Although both methods report generalized ictal-like seizure events consistently, LFP and calcium imaging do not measure identical activity. For example, single and multiunit background activity shown in LFP recording in Control fish was not seen in corresponding calcium trace (Fig. $3 A$, left); 4-AP fish showed frequent high-amplitude spikes in LFP (Fig. $3 A$, middle), but little to no fluorescence change was observed in the recording region (optic tectum/cerebellum; ROls 7-10 in Fig. 3C, middle). These observations reveal the relative advantages and disadvantages of each approach. Compared with LFP recording, GCaMP-based imaging provides superior spatial resolution but inferior detection sensitivity and speed (Chen et al., 2013), which may not effectively detect subthreshold synaptic transmission or capture fast spikes 
seen in LFP recordings. Conversely, LFP recordings are limited to a single recording site in the brain.

4-AP has been reported to induce ictal-like discharges in vitro (Galvan et al., 1982; Avoli et al., 2002) and in vivo (Szente and Pongrácz, 1979; Peña and Tapia, 2000), but it is not a robust state in all conditions (Perreault and Avoli, 1991, 1992; Mattia et al., 1993; Zhu et al., 2008; Avoli and Jefferys, 2016). In this work, ictal-like seizure events were not consistently observed in 4-AP-exposed zebrafish larvae at a concentration of $4 \mathrm{mM}$, except a fatal long-lasting burst after prolonged exposures (data not shown), which is consistent with other zebrafish-based imaging studies (Winter et al., 2017). 4-AP-induced neuronal hyperexcitability revealed by LFP recordings (Fig. 3) and imaging of microcircuit dynamics (Fig. 5) was also in line with previous reported behavioral manifestations in 4-AP-treated zebrafish (Kumar et al., 2016) and provided us with an hyperexcitable state that was not complicated by the presence of ictal-like activity.

When examining neuronal dynamics in optic tectum microcircuits, we detected ensembles of coactive neurons during interictal periods and showed that, in PTZ-treated fish, ensembles were spatially localized, while in 4-APtreated fish, ensembles were smaller (contained less neurons) and dispersed (Fig. 5). Neuronal ensembles could also be detected in Control fish, but the ensemble event occurrence was rare. Similar observations of functional clusters were reported in calcium imaging studies from hippocampal slices prepared from chronically epileptic mice (Muldoon et al., 2013). Interestingly, "microseizures," which are discharges from highly confined neuron groups within ictal onset zones, have been observed in intracranial recordings from microelectrode arrays in human patients with partial epilepsy (Schevon et al., 2008, 2010; Stead et al., 2010). Although precise spatiotemporal information of microdischarge clusters is absent in these studies, it raises an intriguing hypothesis that ictal networks are composed of sparse pathologic microdomains that can generate microseizures, and the spreading of microseizures results in ictal seizures (Stead et al., 2010). Here we employed a wellestablished acute zebrafish seizure model and high-speed calcium imaging with single-cell resolution to map neural activations. This strategy revealed neuronal ensembles in an ictal network (the optic tectum microcircuit), which possibly correspond to human microseizure domains. Future studies using three-dimensional light sheet imaging (Ahrens et al., 2013b; Portugues et al., 2014; Dunn et al., 2016) with enhanced scanning speed could improve the neuron sampling and provide an even better understanding of the role of neuronal ensembles in seizure generation and propagation.

In summary, we established a zebrafish-based calcium imaging platform to evaluate network dynamics underlying recurrent seizures, including network synchronization, seizure propagation and neuronal ensembles within local microcircuits. Future work with improved imaging techniques to explore the interplay between micro-ensembles and macro-seizures, combined with zebrafish models mimicking genetic forms of epilepsy, will provide insights into seizure prediction and suppression.

\section{References}

Afrikanova T, Serruys A-SK, Buenafe OEM, Clinckers R, Smolders I, de Witte PAM, Crawford AD, Esguerra CV (2013) Validation of the zebrafish pentylenetetrazol seizure model: locomotor versus electrographic responses to antiepileptic drugs. PLoS One 8:e54166. CrossRef Medline

Ahrens MB, Li JM, Orger MB, Robson DN, Schier AF, Engert F, Portugues R (2012) Brain-wide neuronal dynamics during motor adaptation in zebrafish. Nature 485:471-477. CrossRef Medline

Ahrens MB, Huang K-H, Narayan S, Mensh BD, Engert F (2013a) Two-photon calcium imaging during fictive navigation in virtual environments. Front Neural Circuits 7:104. CrossRef Medline

Ahrens MB, Orger MB, Robson DN, Li JM, Keller PJ (2013b) Wholebrain functional imaging at cellular resolution using light-sheet microscopy. Nat Methods 10:413-420. CrossRef Medline

Akerboom J, Chen TW, Wardill TJ, Tian L, Marvin JS, Mutlu S, Calderón NC, Esposti F, Borghuis BG, Sun XR, Gordus A, Orger MB, Portugues R, Engert F, Macklin JJ, Filosa A, Aggarwal A, Kerr RA, Takagi R, Kracun S, et al. (2012) Optimization of a GCaMP calcium indicator for neural activity imaging. J Neurosci 32:1381913840. CrossRef Medline

Avoli M, Jefferys JGR (2016) Models of drug-induced epileptiform synchronization in vitro. J Neurosci Methods 260:26-32. CrossRef Medline

Avoli M, D'Antuono M, Louvel J, Köhling R, Biagini G, Pumain R, D'Arcangelo G, Tancredi V (2002) Network and pharmacological mechanisms leading to epileptiform synchronization in the limbic system in vitro. Prog Neurobiol 68:167-207. CrossRef Medline

Baraban SC, Taylor MR, Castro PA, Baier H (2005) Pentylenetetrazole induced changes in zebrafish behavior, neural activity and c-fos expression. Neuroscience 131:759-768. CrossRef Medline

Barbalho PG, Lopes-Cendes I, Maurer-Morelli CV (2016) Indomethacin treatment prior to pentylenetetrazole-induced seizures downregulates the expression of $\mathrm{il} 1 \mathrm{~b}$ and cox 2 and decreases seizurelike behavior in zebrafish larvae. BMC Neurosci 17:12. CrossRef Medline

Baxendale S, Holdsworth CJ, Santoscoy PLM, Harrison MRM, Fox J, Parkin CA, Ingham PW, Cunliffe VT (2012) Identification of compounds with anti-convulsant properties in a zebrafish model of epileptic seizures. Dis Model Mech 5:773-784. CrossRef Medline

Buenafe OE, Orellana-Paucar A, Maes J, Huang H, Ying X, De Borggraeve W, Crawford AD, Luyten W, Esguerra CV, de Witte P (2013) Tanshinone IIA exhibits anticonvulsant activity in zebrafish and mouse seizure models. ACS Chem Neurosci 4:1479-1487. CrossRef Medline

Buzsáki G, Anastassiou CA, Koch C (2012) The origin of extracellular fields and currents-EEG, ECoG, LFP and spikes. Nat Rev Neurosci 13:407-420. CrossRef Medline

Cassar S, Breidenbach L, Olson A, Huang X, Britton H, Woody C, Sancheti P, Stolarik D, Wicke K, Hempel K, LeRoy B (2017) Measuring drug absorption improves interpretation of behavioral responses in a larval zebrafish locomotor assay for predicting seizure liability. J Pharmacol Toxicol Methods 88:56-63. CrossRef Medline

Chen TW, Wardill TJ, Sun Y, Pulver SR, Renninger SL, Baohan A, Schreiter ER, Kerr RA, Orger MB, Jayaraman V, Looger LL, Svoboda K, Kim DS (2013) Ultrasensitive fluorescent proteins for imaging neuronal activity. Nature 499:295-300. CrossRef Medline Copmans D, Orellana-Paucar AM, Steurs G, Zhang Y, Ny A, Foubert K, Exarchou V, Siekierska A, Kim Y, De Borggraeve W, Dehaen W, Pieters L, de Witte PAM (2018) Methylated flavonoids as antiseizure agents: naringenin 4',7-dimethyl ether attenuates epileptic seizures in zebrafish and mouse models. Neurochem Int 112:124133. CrossRef Medline

Dunn TW, Mu Y, Narayan S, Randlett O, Naumann EA, Yang C-T, Schier AF, Freeman J, Engert F, Ahrens MB (2016) Brain-wide mapping of neural activity controlling zebrafish exploratory locomotion. Elife 5:e12741. CrossRef Medline 
Ellis LD, Seibert J, Soanes KH (2012) Distinct models of induced hyperactivity in zebrafish larvae. Brain Res 1449:46-59. CrossRef Medline

Galvan M, Grafe P, Bruggencate GT (1982) Convulsant actions of 4 -aminopyridine on the guinea-pig olfactory cortex slice. Brain Res 241:75-86. CrossRef Medline

Grasse DW, Karunakaran S, Moxon KA (2013) Neuronal synchrony and the transition to spontaneous seizures. Exp Neurol 248:72-84. CrossRef Medline

Greenberg DS, Houweling AR, Kerr JND (2008) Population imaging of ongoing neuronal activity in the visual cortex of awake rats. Nat Neurosci 11:749-751. CrossRef Medline

Griffin A, Hamling KR, Knupp K, Hong S, Lee LP, Baraban SC (2017) Clemizole and modulators of serotonin signalling suppress seizures in Dravet syndrome. Brain 140:669-683. CrossRef Medline

Grone BP, Baraban SC (2015) Animal models in epilepsy research: legacies and new directions. Nat Neurosci 18:339-343. CrossRef Medline

Grosser S, Queenan BN, Lalchandani RR, Vicini S (2014) Hilar somatostatin interneurons contribute to synchronized GABA activity in an in vitro epilepsy model. PLoS One 9:e86250. CrossRef Medline

Hongo Y, Takasu K, Ikegaya Y, Hasegawa M, Sakaguchi G, Ogawa $\mathrm{K}$ (2015) Heterogeneous effects of antiepileptic drugs in an in vitro epilepsy model - a functional multineuron calcium imaging study. Eur J Neurosci 42:1818-1829. CrossRef Medline

Hortopan GA, Dinday MT, Baraban SC (2010) Zebrafish as a model for studying genetic aspects of epilepsy. Dis Model Mech 3:144148. CrossRef Medline

Jiruska $P$, de Curtis M, Jefferys JGR, Schevon CA, Schiff SJ, Schindler K (2013) Synchronization and desynchronization in epilepsy: controversies and hypotheses. J Physiol 591:787-797. CrossRef Medline

Kumar MG, Rowley S, Fulton R, Dinday MT, Baraban SC, Patel M (2016) Altered glycolysis and mitochondrial respiration in a zebrafish model of Dravet syndrome. eNeuro 3: ENEURO.000816.2016. CrossRef Medline

Kuzum D, Takano H, Shim E, Reed JC, Juul H, Richardson AG, de Vries J, Bink H, Dichter MA, Lucas TH, Coulter DA, Cubukcu E, Litt B (2014) Transparent and flexible low noise graphene electrodes for simultaneous electrophysiology and neuroimaging. Nat Commun 5:5259. CrossRef Medline

Li X, Cui D, Jiruska P, Fox JE, Yao X, Jefferys JGR (2007) Synchronization measurement of multiple neuronal populations. J Neurophysiol 98:3341-3348. CrossRef Medline

Liew WC, Orbán L (2014) Zebrafish sex: a complicated affair. Brief Funct Genomics 13:172-187. CrossRef Medline

Lillis KP, Wang Z, Mail M, Zhao GQ, Berdichevsky Y, Bacskai B, Staley KJ (2015) Evolution of network synchronization during early epileptogenesis parallels synaptic circuit alterations. J Neurosci 35:9920-9934. CrossRef Medline

Liou J, Ma H, Wenzel M, Zhao M, Baird-Daniel E, Smith EH, Daniel A, Emerson R, Yuste R, Schwartz TH, Schevon CA (2018) Role of inhibitory control in modulating focal seizure spread. Brain 141: 2083-2097. CrossRef Medline

Martín-Jiménez R, Campanella M, Russell C (2015) New zebrafish models of neurodegeneration. Curr Neurol Neurosci Rep 15:33. CrossRef Medline

Mattia D, Hwa GGC, Avoli M (1993) Epileptiform activity induced by 4-aminopyridine in guinea-pig and rat neocortices. Neurosci Lett 154:157-160. CrossRef Medline

Miller JK, Ayzenshtat I, Carrillo-Reid L, Yuste R (2014) Visual stimuli recruit intrinsically generated cortical ensembles. Proc Natl Acad Sci USA 111:E4053-E4061. CrossRef Medline

Muldoon SF, Soltesz I, Cossart R (2013) Spatially clustered neuronal assemblies comprise the microstructure of synchrony in chronically epileptic networks. Proc Natl Acad Sci USA 110:3567-3572. CrossRef Medline

Muldoon SF, Villette V, Tressard T, Malvache A, Reichinnek S, Bartolomei F, Cossart R (2015) GABAergic inhibition shapes inter- ictal dynamics in awake epileptic mice. Brain 138:2875-2890. CrossRef Medline

Muto A, Kawakami K (2013) Prey capture in zebrafish larvae serves as a model to study cognitive functions. Front Neural Circuits 7:110. CrossRef Medline

Muto A, Ohkura M, Abe G, Nakai J, Kawakami K (2013) Real-time visualization of neuronal activity during perception. Curr Biol 23: 307-311. CrossRef Medline

Orellana-Paucar AM, Afrikanova T, Thomas J, Aibuldinov YK, Dehaen W, de Witte PAM, Esguerra CV (2013) Insights from zebrafish and mouse models on the activity and safety of ar-turmerone as a potential drug candidate for the treatment of epilepsy. PLoS One 8:e81634. CrossRef Medline

Park YS, Hochberg LR, Eskandar EN, Cash SS, Truccolo W (2013) Early detection of human epileptic seizures based on intracortical local field potentials. Int IEEE EMBS Conf Neural Eng 2013:323326.

Patel TP, Man K, Firestein BL, Meaney DF (2015) Automated quantification of neuronal networks and single-cell calcium dynamics using calcium imaging. J Neurosci Methods 243:26-38. CrossRef Medline

Peña F, Tapia R (2000) Seizures and neurodegeneration induced by 4-aminopyridine in rat hippocampus in vivo: role of glutamate- and GABA-mediated neurotransmission and of ion channels. Neuroscience 101:547-561. CrossRef Medline

Penfield W, Jasper H (1954) Epilepsy and the functional anatomy of the human brain. Oxford, UK: Little, Brown \& Co.

Perreault P, Avoli M (1991) Physiology and pharmacology of epileptiform activity induced by 4-aminopyridine in rat hippocampal slices. J Neurophysiol 65:771-785. CrossRef Medline

Perreault P, Avoli M (1992) 4-aminopyridine-induced epileptiform activity and a GABA-mediated long-lasting depolarization in the rat hippocampus. J Neurosci 12:104-115. CrossRef Medline

Portugues R, Feierstein CE, Engert F, Orger MB (2014) Whole-brain activity maps reveal stereotyped, distributed networks for visuomotor behavior. Neuron 81:1328-1343. CrossRef Medline

Rahn JJ, Bestman JE, Josey BJ, Inks ES, Stackley KD, Rogers CE, Chou CJ, Chan SSL (2014) Novel Vitamin K analogs suppress seizures in zebrafish and mouse models of epilepsy. Neuroscience 259:142-154. CrossRef Medline

Ramirez IBR, Pietka G, Jones DR, Divecha N, Alia A, Baraban SC, Hurlstone AFL, Lowe M (2012) Impaired neural development in a zebrafish model for Lowe syndrome. Hum Mol Genet 21:17441759. CrossRef Medline

Rosch RE, Hunter PR, Baldeweg T, Friston KJ, Meyer MP (2018) Calcium imaging and dynamic causal modelling reveal brain-wide changes in effective connectivity and synaptic dynamics during epileptic seizures. PLoS Comput Biol 14:e1006375. CrossRef Medline

Rossi LF, Wykes RC, Kullmann DM, Carandini M (2017) Focal cortical seizures start as standing waves and propagate respecting homotopic connectivity. Nat Commun 8:217. CrossRef Medline

Rupprecht P, Prendergast A, Wyart C, Friedrich RW (2016) Remote z-scanning with a macroscopic voice coil motor for fast 3D multiphoton laser scanning microscopy. Biomed Opt Express 7:16561671. CrossRef Medline

Schevon CA, Ng SK, Cappell J, Goodman RR, McKhann G, Waziri A, Branner A, Sosunov A, Schroeder CE, Emerson RG (2008) Microphysiology of epileptiform activity in human neocortex. J Clin Neurophysiol off Publ Am Electroencephalogr Soc 25:321-330. CrossRef Medline

Schevon CA, Goodman RR, McKhann G, Emerson RG (2010) Propagation of epileptiform activity on a submillimeter scale. J Clin Neurophysiol 27:406-411. CrossRef Medline

Schmidt H, Petkov G, Richardson MP, Terry JR (2014) Dynamics on networks: the role of local dynamics and global networks on the emergence of hypersynchronous neural activity. PLoS Comput Biol 10:e1003947. CrossRef Medline

Schultz SR, Kitamura K, Post-Uiterweer A, Krupic J, Häusser M (2009) Spatial pattern coding of sensory information by climbing 
fiber-evoked calcium signals in networks of neighboring cerebellar Purkinje cells. J Neurosci 29:8005-8015. CrossRef Medline

Semmelhack JL, Donovan JC, Thiele TR, Kuehn E, Laurell E, Baier H (2014) A dedicated visual pathway for prey detection in larval zebrafish. Elife 3:e04878. CrossRef Medline

Siebel AM, Menezes FP, da Costa Schaefer I, Petersen BD, Bonan CD (2015) Rapamycin suppresses PTZ-induced seizures at different developmental stages of zebrafish. Pharmacol Biochem Behav 139:163-168. CrossRef Medline

Stead M, Bower M, Brinkmann BH, Lee K, Marsh WR, Meyer FB, Litt B, Van Gompel J, Worrell GA (2010) Microseizures and the spatiotemporal scales of human partial epilepsy. Brain 133:27892797. CrossRef Medline

Stewart AM, Braubach O, Spitsbergen J, Gerlai R, Kalueff AV (2014) Zebrafish models for translational neuroscience research: from tank to bedside. Trends Neurosci 37:264-278. CrossRef Medline

Szente M, Pongrácz F (1979) Aminopyridine-induced seizure activity. Electroencephalogr Clin Neurophysiol 46:605-608. CrossRef Medline

Tao L, Lauderdale JD, Sornborger AT (2011) Mapping functional connectivity between neuronal ensembles with larval zebrafish transgenic for a ratiometric calcium indicator. Front Neural Circuits 5:2. CrossRef Medline

Thiele TR, Donovan JC, Baier H (2014) Descending control of swim posture by a midbrain nucleus in zebrafish. Neuron 83:679-691. CrossRef Medline

Tian L, Hires SA, Mao T, Huber D, Chiappe ME, Chalasani SH, Petreanu L, Akerboom J, McKinney SA, Schreiter ER, Bargmann Cl, Jayaraman V, Svoboda K, Looger LL (2009) Imaging neural activity in worms, flies and mice with improved GCaMP calcium indicators. Nat Methods 6:875-881. CrossRef Medline
Trevelyan AJ, Sussillo D, Watson BO, Yuste R (2006) Modular propagation of epileptiform activity: evidence for an inhibitory veto in neocortex. J Neurosci 26:12447-12455. CrossRef Medline

Truccolo W, Donoghue JA, Hochberg LR, Eskandar EN, Madsen JR, Anderson WS, Brown EN, Halgren E, Cash SS (2011) Singleneuron dynamics in human focal epilepsy. Nat Neurosci 14:635641. CrossRef Medline

Truccolo W, Ahmed OJ, Harrison MT, Eskandar EN, Cosgrove GR, Madsen JR, Blum AS, Potter NS, Hochberg LR, Cash SS (2014) Neuronal ensemble synchrony during human focal seizures. J Neurosci 34:9927-9944. CrossRef Medline

Turrini L, Fornetto C, Marchetto G, Müllenbroich MC, Tiso N, Vettori A, Resta F, Masi A, Mannaioni G, Pavone FS, Vanzi F (2017) Optical mapping of neuronal activity during seizures in zebrafish. Sci Rep 7:3025. CrossRef Medline

Weiss SA, Alvarado-Rojas C, Bragin A, Behnke E, Fields T, Fried I, Engel J, Staba R (2016) Ictal onset patterns of local field potentials, high frequency oscillations, and unit activity in human mesial temporal lobe epilepsy. Epilepsia 57:111-121. CrossRef Medline

Wenzel M, Hamm JP, Peterka DS, Yuste R (2017) Reliable and elastic propagation of cortical seizures in vivo. Cell Rep 19:2681-2693. CrossRef Medline

Winter MJ, Windell D, Metz J, Matthews P, Pinion J, Brown JT, Hetheridge MJ, Ball JS, Owen SF, Redfern WS, Moger J, Randall $A D$, Tyler CR (2017) 4-dimensional functional profiling in the convulsant-treated larval zebrafish brain. Sci Rep 7:6581. CrossRef Medline

Zhu L, Polley N, Mathews GC, Delpire E (2008) NKCC1 and KCC2 prevent hyperexcitability in the mouse hippocampus. Epilepsy Res 79:201-212. CrossRef Medline 